\title{
Synthesis and Characterization of Copolymers of Methyl Methacrylate and 2-Ethoxyethyl Methacrylate
}

\author{
M. Manju ${ }^{1}$, M.K. Veeraiah, ${ }^{2, *}$, S. Prasannakumar ${ }^{3}$, N.M. Made Gowda ${ }^{4}$, B.S. Sherigara ${ }^{5}$ \\ ${ }^{1}$ Department of Chemistry, Sri Krishna Institute of Technology, Bangalore, India \\ ${ }^{2}$ Department of Chemistry, Sri Siddhartha Institute of Technology, Tumkur, India \\ ${ }^{3}$ Clov Chem. India Private Limited, Harohalli, Bangalore, India \\ ${ }^{4}$ Department of Chemistry, Western Illinois University, One University Circle, Macomb IL, 61455, USA \\ ${ }^{5}$ Department of Industrial Chemistry, Kuvempu University, Shankaraghatta, Shivamogga, India
}

\begin{abstract}
The free-radical initiated copolymerizations of methyl methacrylate (MMA) with 2-ethoxyethyl methacrylate (2-EOEMA) were carried out using 2,2-azo-bisisobutyronitrile (AIBN) as the initiator in 1,4-dioxane solutions. The copolymer products were characterized by IR, ${ }^{1} \mathrm{H}-\mathrm{NMR}$, and ${ }^{13} \mathrm{C}-\mathrm{NMR}$ spectroscopic techniques. The reactivity ratios of the monomers were computed by the Fineman-Rose (F-R) and Kelen-Tudos (K-T) methods at lower conversion, using the IR data. The results are in good agreement with each other and the mean reactivity ratios for MMA/EOEMA copolymers are $r_{1}=0.8436, r_{2}=0.7751$, and $r_{1} r_{2}=0.6614$. The reactivity ratios indicate the formation of random copolymers, which have been supported by the azeotropic composition evaluations. The distribution of monomer sequence along the copolymer chain has been calculated using a statistical method based on the reactivity ratios. The probability of finding the mean sequence lengths of 2-EOEMA and MMA units has also been evaluated.
\end{abstract}

Keywords Methyl Methacrylate, 2-Ethoxyethyl Methacrylate, 2,2-Azo-Bis-Isobutyronitrile, Reactivity Ratio, Co-Monomer Probability Sequence, IR, NMR

\section{Introduction}

Free radical copolymerization is a valuable tool for tailoring the properties of polymeric materials for a broad range of applications. For statistical copolymers, the monomer sequence distribution and compositional heterogeneity in and among the copolymer chains have a profound influence on the behavior and physical properties of the materials[1-7].

The acrylic monomer, methyl methacrylate (MMA; $\left.\mathrm{CH}_{2}=\mathrm{C}\left(\mathrm{CH}_{3}\right) \mathrm{COOCH}_{3}\right)$ has been widely used for applications in various fields[8-12]. The MMA based polymers have good biocompatibility, low toxicity, good film forming and adhesive characteristics[13]. It is also used as a comonomer in surface-active copolymerization mainly because of its good amphilic character[8-9]. Methyl methacrylate as a monomer contains a highly polar ester group, which confirms the hydrophilic nature while the methylene and methane groups in the main chain and side chain support the hydrophobic nature, respectively[10]. Methyl methacrylate and acrylate based copolymers are extensively studied by many investigators in biomedical applications such as membranes for ultra filtration/drug delivery, contact lenses and anticoagulant films[13]. Another alkene monomer,

* Corresponding author:

veeraiahmk@gmail.com (M.K. Veeraiah)

Published online at http://journal.sapub.org/ajps

Copyright (C) 2012 Scientific \& Academic Publishing. All Rights Reserved
2-Ethoxyethyl methacrylate (2-EOEMA; $\mathrm{H}_{2} \mathrm{C}=\mathrm{C}\left(\mathrm{CH}_{3}\right)$ $\mathrm{CO}_{2} \mathrm{CH}_{2} \mathrm{CH}_{2} \mathrm{OC}_{2} \mathrm{H}_{5}$ ) is a dual functional group monomer, which has both ether and ester groups as compared to most of the vinyl acrylic monomers; these groups not only impart flexibility into the polymer, but also improve its process ability and handling[14] and improve compatibility in blends due to hydrogen bonding[15]. Because of its soft and flexible nature, 2-EOEMA based copolymers and terpolymers could be a better candidate as surfactant $[16,17]$.

The chemical structure of a co-polymer depends on the two-monomer units, which are distributed along macromolecular chains. This distribution is a direct consequence of each monomer's reactivity in the polymer molecules[18]. Determination of the monomer reactivity ratios with small confidence intervals requires sensitive analytical techniques, careful planning of experiments, and the use of statistically valid methods of estimation[19-20]. In order to calculate the rate of polymerization or polymer productivity and copolymer composition, monomer reactivity ratios must be known[19]. Reactivity ratios were determined by F-R[21] and K-T[22] methods using the data obtained by IR analysis. The present investigation describes the synthesis of the MMA/EOEMA copolymer by free-radical polymerization and the polymer structure was characterized by IR, ${ }^{1} \mathrm{H}-\mathrm{NMR}$ and ${ }^{13} \mathrm{C}$-NMR spectroscopic techniques. Reactivity ratios calculated using the IR data are in good agreement with each other. 


\section{Experimental}

\subsection{Materials}

Methyl methacrylate (MMA), 2-ethoxyethyl methacylate (2-EOEMA), and 2, 2-Azo-bis-isobutyronitrile (AIBN) were obtained from Sigma-Aldrich Chemical Co., USA. Both MMA and 2-EOEMA, were washed with a dilute aqueous alkali solution $(5 \% \mathrm{NaOH})$ followed by water, dried over anhydrous $\mathrm{CaCl}_{2}$ in a desiccator and stored below $0^{\circ} \mathrm{C}$. The organic solvents such as acetone, chloroform, tetrahydrofurane, dimethylsulfoxide, dimethylformamide, dimethylacetamide, ethyl acetate, isobutyl acetate, benzene, hexane, and 1, 4-dioxane were of AR Grade with $99 \%$ purity. They were used as received from E. Merck Chemicals, Mumbai, India.

\subsection{Synthesis}

Copolymerization reactions of varying compositions of monomers[MMA/EOEMA: (A) 25:75, (B) 33.3:66.7, (C) 50:50, (D) 66.7:33.3, (E) 75:25] were carried out in 1,4-dioxane solvent at $60^{\circ} \mathrm{C}$ under the inert nitrogen atmosphere (Scheme I) For each reaction, calculated amounts of 2-EOEMA, MMA, 1,4-dioxane and 0.5\% AIBN were taken in a $250 \mathrm{~mL}$ three-necked round bottom flask, placed in an oil bath maintained at $60^{\circ} \mathrm{C}$ with continuous stirring. The copolymerization was allowed to proceed to high conversion (less than 15\%) under nitrogen atmosphere. The polymerization reaction was stopped by cooling the reaction mixture to room temperature. The polymer product obtained was precipitated in a diethyl ether/hexane mixture to ensure complete removal of residual monomers. Copolymer samples were suction-filtered and dried in vacuum at $40^{\circ} \mathrm{C}$ until constant weight.

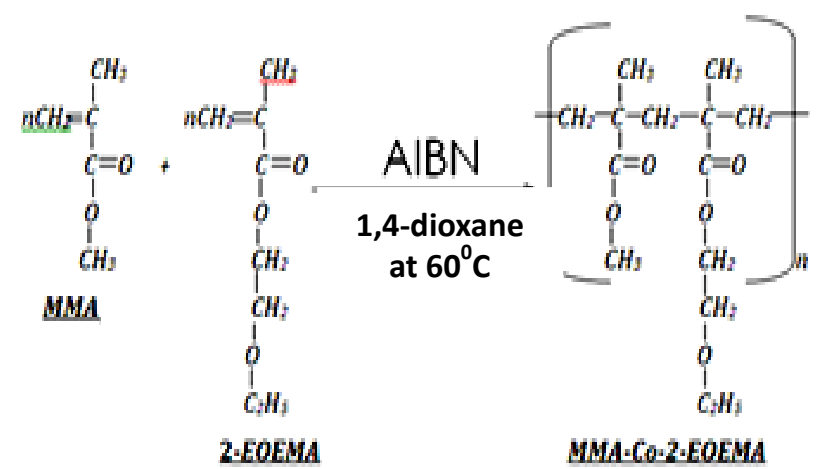

Scheme 1. General reaction for the synthesis of MMA/EOEMA copolymer

\subsection{Solubility Measurement}

Solubilities of polymers were tested in polar and non-polar organic solvents. To a $5.0 \mathrm{~mL}$ solvent, a known amount of the copolymer sample $(5-10 \mathrm{mg})$ was added and kept stirred for $24 \mathrm{hr}$. The observations showed that the copolymers were completely soluble in most of the polar solvents such as acetone, chloroform, tetrahydrofurane, dimethylsulfoxide, dimethylformamide, dimethylacetamide, ethyl acetate, iso- butyl acetate, and 1,4-dioxane. They were insoluble in non-polar solvents like hexane, cyclohexane, carbon tetrachloride, and benzene and in highly polar water.

\subsection{Spectroscopic Analysis of Copolymers}

Copolymers were characterized by: i) Fourier-Transform infrared (FT-IR) spectra in acetone recorded on a Simadzu $1800 \mathrm{~S}$ spectrometer at $2 \mathrm{~cm}^{-1}$ resolution with 64 scans over the spectral range of 4000-400 $\mathrm{cm}^{-1}$; ii) Proton-NMR) and ${ }^{13} \mathrm{C}$-NMR spectra in $\mathrm{CDCl}_{3}$ or $\mathrm{DMSO}-\mathrm{d}_{6}$ as solvent on a Bruker AMX-400 spectrometer using tetramethylsilane (TMS) as the internal standard at the Indian Institute of Science, Bangalore, India.

\section{Results and Discussion}

\subsection{Copolymers characterization}

Copolymers of MMA/EOEMA having different compositions were prepared using AIBN as a free-radical initiator in 1,4-dioxane solutions under nitrogen atmosphere under $60^{\circ} \mathrm{C}$.

\subsubsection{Infrared Spectral Study}

Infrared spectra of the new copolymers are presented in Fig. 1. A strong absorption peak at $1731.7 \mathrm{~cm}^{-1}$ is due to the carbonyl ester group of MMA and 2-EOEMA units of the polymer. The peak in the range, $1125.4 \mathrm{~cm}^{-1}-1271.3 \mathrm{~cm}^{-1}$, is due to a strong absorption caused by an asymmetric C-O-C stretching mode in the vinyl ether of 2-EOEMA unit. The peak at $995.95 \mathrm{~cm}^{-1}$ is due to the alkene $\left(\mathrm{C}_{2} \mathrm{H}_{4}\right)$ group of the 2-EOEMA unit. The peaks at $1386.18 \mathrm{~cm}^{-1}$ and $1451.56 \mathrm{~cm}^{-1}$ are due to the Alkyl (-C-H) group of both MMA and 2-EOEMA units. Peaks at $1766.75 \mathrm{~cm}^{-1}$ and $1789.59 \mathrm{~cm}^{-1}$ are due to ketone $(\mathrm{C}=\mathrm{O})$ group of both MMA and 2-EOEMA units.

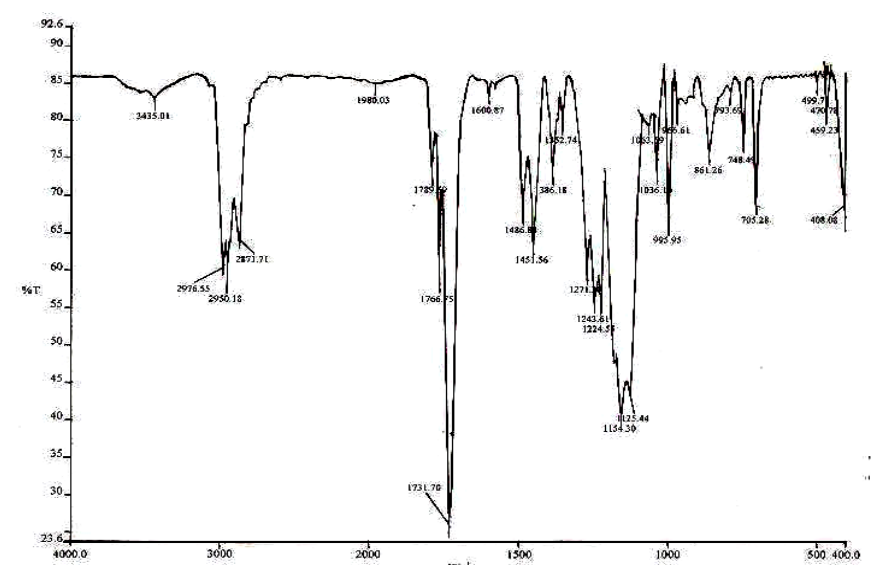

Figure 1. IR Spectrum of MMA/EOEMA copolymer

\subsubsection{Nuclear Magnetic Resonance Spectroscopy}

The ${ }^{1} \mathrm{H}-\mathrm{NMR}$ spectrum of a copolymer product is shown in Fig. 2. The main methylene proton signals of both the MMA and 2-EOEMA units resonate at $2.09-1.89 \mathrm{ppm}$, 
which overlap with the type of compositional and configurational sequences. Hence, it is difficult to assign these. Similarly, methyl proton signals of 2- EOEMA observed at o 0.88-1.29 ppm are overlapping with each other. Two $\left(-\mathrm{CH}_{2}-\mathrm{C}=\mathrm{O}\right)$ proton signals of the keto group of both MMA and 2-EOEMA are observed at $2.79 \mathrm{ppm}$ while a multiplet of three methylene $\left(\mathrm{CH}_{2}, \mathrm{CH}_{2}, \mathrm{CH}_{2}\right)$ protons for 2-EOEMA appear at $23.5-3.69 \mathrm{ppm}$. The absorption of methylene protons $\left(-\mathrm{CH}_{2}-\mathrm{O}-\mathrm{CH}_{2}-\right)$ of the ether group of 2-EOEMA occurs at $\partial 4.12 \mathrm{ppm}$. The multiplet for protons of conjugated olefins of the copolymer resonates at $27.35-8.10$ ppm, whereas the methyl ester group protons of MMA $\left(\mathrm{COO}-\mathrm{CH}_{3}\right)$ units resonate around $3.35 \mathrm{ppm}$, respectively. The structure of the copolymer was further confirmed by ${ }^{13} \mathrm{C}-\mathrm{NMR}$ spectroscopy (Fig. 3). The carbonyl carbon
$(>\mathrm{C}=\mathrm{O})$ signals of both the MMA and 2-EOEMA units are appearing at $\partial 205.2 \mathrm{ppm}$. The signals of ester group carbons (R-COO-R ${ }^{1}$ ) of both the MMA and 2-EOEMA units appear at $\partial 162.8 \mathrm{ppm}$. The olefinic carbon absorptions of 2-EOEMA appearing in the region, $\partial 134.7 \mathrm{ppm}-125.5$ ppm are quite complex. The ether $(\mathrm{C}-\mathrm{O}-\mathrm{C})$ group carbons of 2-EOEMA occur in the region, $267.4 \mathrm{ppm}-64.1 \mathrm{ppm}$, whereas carbon absorptions of the $-\mathrm{CH}$ and $-\mathrm{O}-\mathrm{CH}_{3}$ groups of MMA and 2-EOEMA appear at $251.14 \mathrm{ppm}$. The side chain methylene carbons of both the MMA and 2-EOEMA absorb at $\partial 29.48 \mathrm{ppm}-28.34 \mathrm{ppm}$. The spectral region of $\partial$ $67.63 \mathrm{ppm}-14.76 \mathrm{ppm}$ is quite complex and overlapping may be due to aliphatic carbon resonance in the backbone and side chain of the copolymer. Furthermore, two methyl carbons of 2-EOEMA resonate at $\partial 14.76 \mathrm{ppm}$.

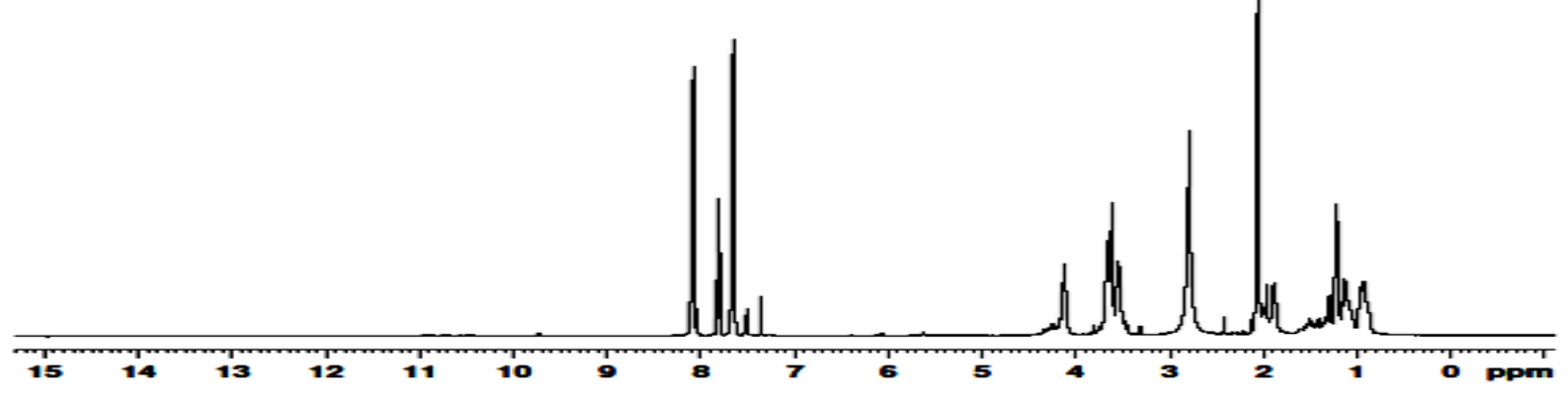

Figure 2. ${ }^{1} \mathrm{H}-\mathrm{NMR}$ Spectrum of MMA/EOEMA copolymer

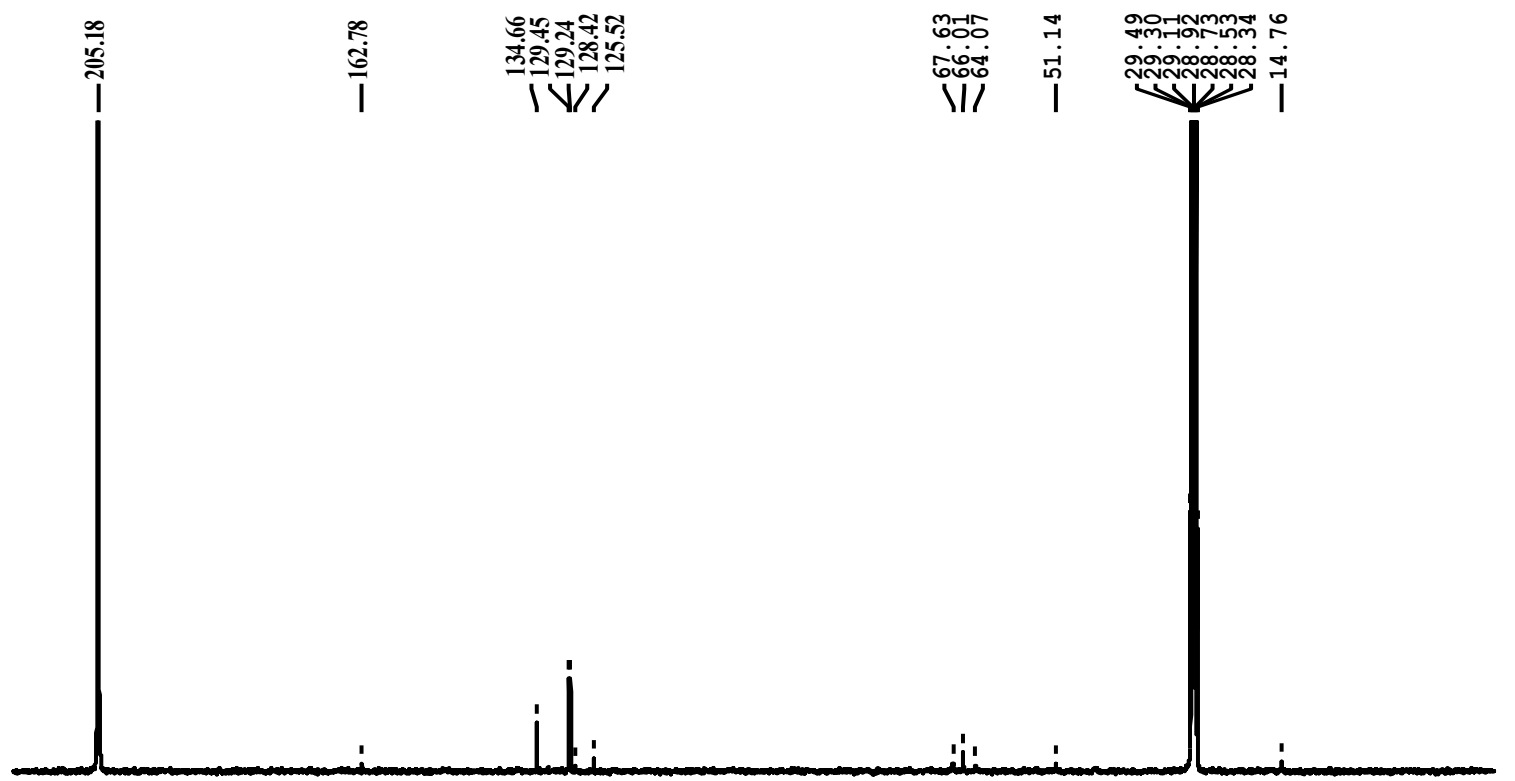

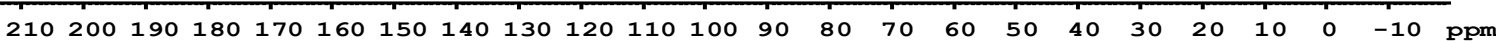

Figure 3. ${ }^{13} \mathrm{C}-\mathrm{NMR}$ Spectrum of MMA/EOEMA copolymer 


\subsubsection{Copolymer Composition}

The composition of monomers in the polymer product was determined by IR spectroscopy through recorded absorption bands for comonomers[23,24]. Pure carbonyl group of the MMA/2-EOEMA copolymer has a characteristic, broad infrared absorption band at $1732 \mathrm{~cm}-1$, while the ether group of 2-EOEMA is at $1152 \mathrm{~cm}-1$. These carbonyl absorbance peaks in the copolymers of different composition are shown in Fig. 4. It is evident that with an increase in 2-EOEMA content, peak-1 increases correspondingly. Using the absorbance of carboxyl groups of MMA and EOEMA of all copolymer compositions, the concentrations of 2-EOEMA and MMA in the copolymer were obtained. The product compositions obtained by the IR method were analyzed and the results calculated according to the following equations[25].
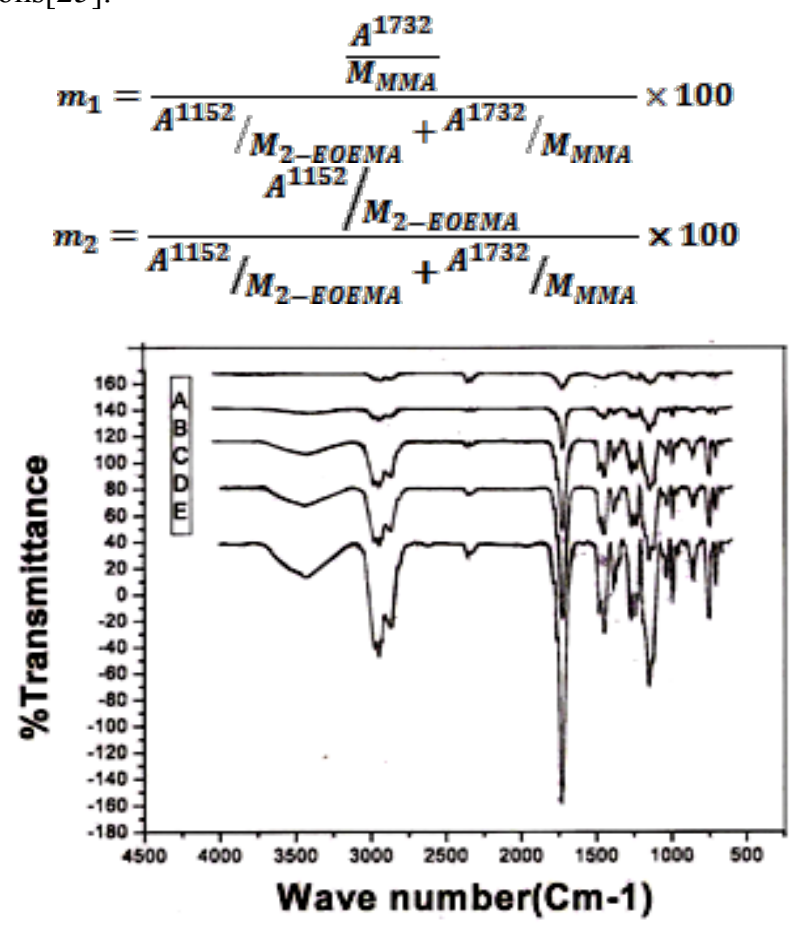

Figure 4. FT-IR spectra of MMA/2-EOEMA copolymers of different compositions of MMA/EOEMA: (A) 25:75, (B) 33.3:66.7, (C) 50:50, D) 66.7:33.3, (E) $75: 25$

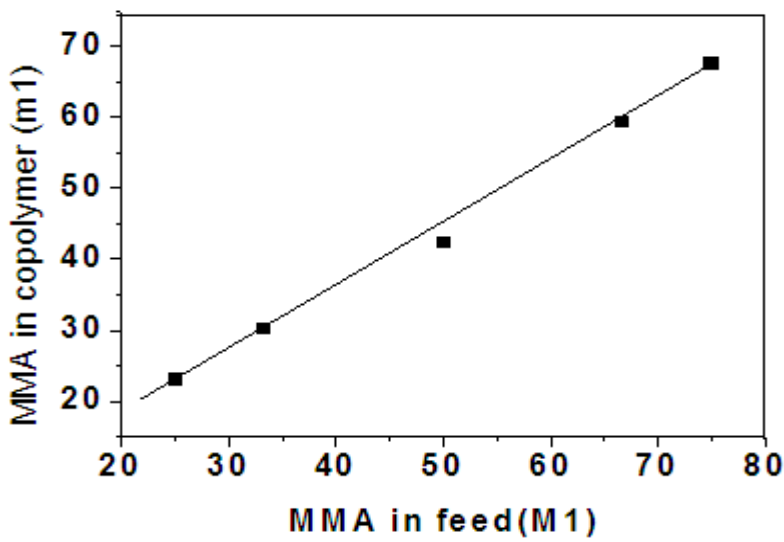

Figure 5. Plot of mol\% MMA $\left(\mathrm{M}_{1}\right)$ in the reaction mixture vs. $\mathrm{mol} \%$ MMA $\left(\mathrm{m}_{1}\right)$ in copolymer

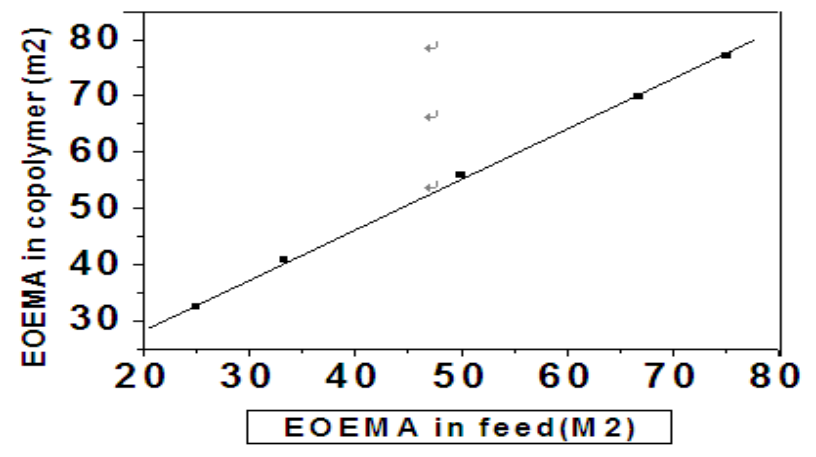

Figure 6. Plot of mol\% of 2-EOEMA $\left(\mathrm{M}_{2}\right)$ in the reaction mixture vs. mol\% 2-EOEMA $\left(\mathrm{m}_{2}\right)$ in copolymer

where absorbance, $A=\log (1 / T), T=\%$ transmittance; $\mathrm{M}_{\mathrm{MMA}}$ and $\mathrm{M}_{2 \text {-EOEMA }}$ are molecular weights of monomer units. Compositions obtained by the IR method were compared (Table 1). Plots of mol\% of MMA $\left(\mathrm{M}_{1}\right)$ and 2-EOEMA $\left(\mathrm{M}_{2}\right)$ in the reaction mixture vs. mol\% of MMA $\left(\mathrm{m}_{1}\right)$ and 2-EOEMA $\left(\mathrm{m}_{2}\right)$ in copolymers are shown in Figs. 5 and 6.

Table 1. Monomer and copolymer compositions

\begin{tabular}{|c|c|c|c|}
\hline \multicolumn{2}{|c|}{ Monomer (mol \%) } & \multicolumn{2}{c|}{ Copolymer composition (mol \%) } \\
\hline MMA (M1) & EOEMA (M2) & MMA(m1) & EOEMA (m2) \\
\hline 25.0 & 75.0 & 23.0 & 77.0 \\
\hline 33.3 & 66.7 & 30.1 & 69.9 \\
\hline 50.0 & 50.0 & 42.2 & 55.8 \\
\hline 66.7 & 33.3 & 59.2 & 40.8 \\
\hline 75.0 & 25.0 & 67.5 & 32.5 \\
\hline
\end{tabular}

\subsubsection{Monomer Reactivity Ratio}

The comonomer composition sequence is one of the main factors that influences copolymer behavior and properties. The copolymer composition depends on the monomer feed composition and on the relative monomer reactivity. Therefore, it is very important to study the comonomer reactivity in these systems[26]. Copolymerization reactivity ratios of MMA and 2-EOEMA in the products were determined using the standard Fineman-Rose (F-R)[21] and Kelen-Tudos (K-T)[22] methods based on IR spectroscopy. The equations (1) and (2) were used for F-R and K-T methods, respectively.

$$
\mathrm{G}=\mathrm{Fr} 1-\mathrm{r} 2
$$

where $\mathrm{r} 1$ and $\mathrm{r} 2$ are the reactivity ratios relating to the monomers MMA and 2-EOEMA, respectively. G and F are F-R parameters. A F-R plot of G vs. F is shown in Fig. 7.

$$
\eta=(\mathrm{r} 1+\mathrm{r} 2 / \alpha) \xi-(\mathrm{r} 2 / \alpha)
$$

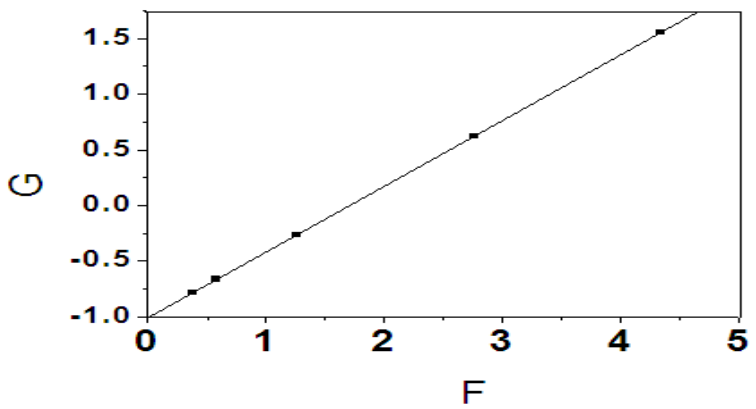

Figure 7. F-R plot of G vs. F 


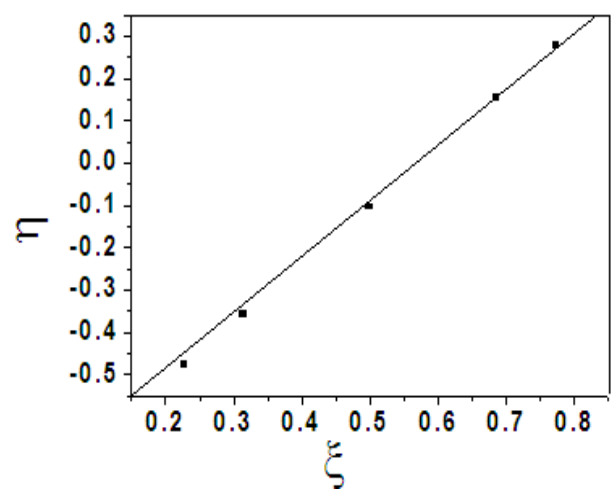

Figure 8. K-T plot of. $\eta$ vs. $\xi$

where $\eta, \xi$ and $\alpha$ are K-T parameters, which are mathematical functions of $\mathrm{G}$ and $\mathrm{F}$ as indicated and presented in Table 2. A K-T plot of $\eta$ vs. $\xi$ is shown in Fig. 8. The rate of polymerization depends on the nature of the acrylate. This can be understood from the value of $1 / \mathrm{r}$ that gives a measure of the reactivity of the acrylate towards 2-EOEMA radical. The value of $1 / \mathrm{r} 1$ copolymer is 1.187 .

\subsubsection{Azeotropic Composition}

The shapes of the azeotropic compositions of the copolymer systems and distribution of monomer units are random. The azeotropic composition $\left(\mathrm{N}_{1}\right)$ was determined by equation (3).

$$
N_{1}=\frac{\left(1-r_{\mathbf{2}}\right)}{\left(2-r_{1}-r_{\mathbf{2}}\right)}
$$

For the system, MMA/2-EOEMA, the mean value of 0.5898 obtained indicates that the copolymer is richer in MMA below this point and richer in 2-EOEMA above this point. This behavior also suggests the random distribution of monomers in the polymer. In the present case, the product $r_{1} r_{2}<1$ indicates that the copolymer is random.

\subsubsection{Copolymer Microstructure}

The copolymer microstructure and sequence distribution of monomers in the formation of the copolymer were evaluated. The probability of finding the sequence of $n$ EOEMA and $n$ MMA units is calculated using the following equations:

$$
\begin{aligned}
\mathrm{N}_{\text {MMA }(\mathrm{n})} & =\mathrm{P}_{11}{ }^{\mathrm{n}-1}\left(1-\mathrm{p}_{11}\right) \\
\mathrm{N}_{\operatorname{EOEMA}(\mathrm{n})} & =\mathrm{P}_{22}{ }^{\mathrm{n}-1}\left(1-\mathrm{p}_{11}\right)
\end{aligned}
$$

where $P_{11}$ and $P_{22}$ are probabilities of MMA and EOEMA units. These probabilities in Table 3 are calculated using equations (6) and (7).

$$
\begin{gathered}
P_{11}=\frac{r_{1} R}{r_{1} R+r_{1}} \\
P_{22}=\frac{r_{2}}{R+r_{2}}
\end{gathered}
$$

where $\mathrm{R}$ is the mole ratio of MMA-to-2-EOEMA in the feed.

The values of $\mathrm{N}_{\mathrm{MMA}(\mathrm{n})}$ and $\mathrm{N}_{\text {EOEMA(n) }}$ shown in Figs. 4 and 5 were calculated for the copolymers at an equimolar feed. In the present investigation, it was observed that the MMA/EOEMA copolymer contains predominantly a sequence of 2-EOEMA, which is in agreement with higher reactivity of 2-EOEMA. The mean sequence lengths $\mu \mathrm{MMA}$ and $\mu$ EOEMA were also calculated using equations (8) and (9).

$$
\begin{array}{r}
\mu \mathrm{MMA}=1+\mathrm{r}_{1}\left(\mathrm{M}_{1} / \mathrm{M}_{2}\right) \\
\mu \mathrm{EOEMA}=1+\mathrm{r}_{2}\left(\mathrm{M}_{2} / \mathrm{M}_{1}\right)
\end{array}
$$

Table 2. F-R and K-T parameters for MMA/E-OEMA copolymers from IR data

\begin{tabular}{|c|c|c|c|c|c|c|}
\hline Sample no & $\mathrm{X}=\mathrm{M}_{1} / \mathrm{M}_{2}$ & $\mathrm{Y}=\mathrm{m}_{1} / \mathrm{m}_{2}$ & $\mathrm{G}=\mathrm{x}(\mathrm{y}-1) / \mathrm{y}$ & $\mathrm{F}=\mathrm{x}^{2} / \mathrm{y}$ & $\eta=\mathrm{G} /(\alpha+\mathrm{F})$ & $\xi=\mathrm{F} /(\alpha+\mathrm{F})^{*}$ \\
\hline $\mathrm{A}$ & 0.3333 & 0.298701 & -0.78253 & 0.3719 & -0.4768 & 0.2266 \\
\hline $\mathrm{B}$ & 0.4999 & 0.430615 & -0.66106 & 0.5804 & -0.3573 & 0.3138 \\
\hline $\mathrm{C}$ & 1.000 & 0.792115 & -0.26244 & 1.2624 & -0.1037 & 0.4986 \\
\hline $\mathrm{D}$ & 2.003 & 1.451 & 0.6226 & 2.765 & 0.15431 & 0.6853 \\
\hline $\mathrm{E}$ & 3.000 & 2.077 & 1.5556 & 4.333 & 0.2776 & 0.7734 \\
\hline
\end{tabular}

$$
* \alpha=\left(\mathrm{F}_{\min } . \mathrm{F}_{\max }\right)^{1 / 2}=1.269485
$$

Table 3. Monomer reactivity ratios for MMA/E-OEMA Copolymer by F-R and K-T methods

\begin{tabular}{|c|c|c|c|c|c|c|}
\hline Method & $\mathrm{r}_{1}$ (EOEMA) & $\mathrm{r}_{2}$ (MMA) & $1 / \mathrm{r}_{1}$ & $1 / \mathrm{r}_{2}$ & $\mathrm{r}_{1} \mathrm{r}_{2}$ & $\mathrm{~N}_{1}$ \\
\hline F-R method & 0.87640 & 1.005 & 1.1410 & 0.9953 & 0.8805 & 0.04774 \\
\hline K-T method & 0.81081 & 0.54556 & 1.2333 & 1.8330 & 0.4423 & 0.7061 \\
\hline Mean & 0.84361 & 0.7751 & 1.1872 & 1.4141 & 0.661 & 0.5898 \\
\hline
\end{tabular}

Table 4. Statistical data for MMA/EOEMA copolymers

\begin{tabular}{|c|c|c|c|c|}
\hline Sample no. & P11 & P22 & $\mu_{\text {EOEMA }}$ & $\mu_{\text {MMA }}$ \\
\hline A & 0.954697 & 3.100793 & 1.281203 & 3.32542 \\
\hline B & 1.093555 & 2.325583 & 1.421171 & 2.552608 \\
\hline C & 1.843608 & 1.55028 & 1.843608 & 1.77514 \\
\hline D & 4.855617 & 1.16213 & 2.689749 & 1.386989 \\
\hline E & 9.843608 & 1.03352 & 3.530823 & 1.25838 \\
\hline
\end{tabular}


The values of $\mu \mathrm{MMA}$ and $\mu$ EOEMA presented in Table 4 show that the $\mu$ EOEMA value increases from 1.281203 to 3.530823 in the copolymer with an increase of 2-EOEMA concentration in the feed. The higher 2-EOEMA content found in the synthesized copolymer correlated with the calculated $r_{1}$ and $r_{2}$ values indicating that the MMA/EOEMA composition is enriched with the EOEMA monomer.

\section{Conclusions}

Copolymers of MMA and 2-EOEMA were synthesized using AIBN as a radical initiator in solution. The copolymers obtained show good solubility in most of the polar solvents and insoluble in non-polar solvents. The characterization of copolymers performed by IR, ${ }^{1} \mathrm{H}-\mathrm{NMR}$ and ${ }^{13} \mathrm{C}-\mathrm{NMR}$ techniques confirms the chemical structure and composition.

The reactivity ratios determined by two standard methods using IR data are in good agreement with each other. Calculated reactivity ratios indicate that 2-EOEMA is more reactive than MMA. The monomer sequence distributions calculated from the statistical method also indicates the copolymer formation with predominately-random distribution of the monomers with a higher content of 2-EOEMA units in the polymer chain. However, reactivity of the monomer depends on its strength and nature of the functional groups present.

\section{REFERENCES}

[1] Moad, G.; Solomon, D.H. The Chemistry of Radical Polymerization, 2nd ed.; Elsevier: Amsterdam, 2006

[2] El-Newehy, M.H.; Al-Deyab, S.S.; Al-Hazmi, A.M.; 2010 , Reactivity Ratios for Organotin Copolymer Systems. Molecules, 15, 2749-2758

[3] Debashish, R.; Aman, U.; Brent S. Suin. J.; 2009, Macromolecules, 42 (20), 7701-7708

[4] Phillip, D.H.; Roger, L.K.; Daniel, J.A.; Edmund, M.C.; Timothy, T.W., 2007, Macromolecules, 40 (20), 7061-7064

[5] Xia, T.; Guang, W.; Armand, S.; Yue, Z., 2005, J. Phys.Chem. B, 109, 20281-20287

[6] Gallado, A.; Lemus, A.R.; San, R.J.; Cifuentes, A.; Diezmasa, J.C., 1999, J. Macromolecules, 32,610-617
[7] Brar, A.S.; Kumar, R. J.; 2002, Polym.Sci., part A: poly.Chem., 40, 2225-2236

[8] Radic, D.; Gargallo, L.; 1997, J. Macromolecules, 30,817

[9] Khosrou, A.; Ali M.; Mohsen A.; Mozhgan, B.; Farideh, G.P.; 2005, Iranian Journal of Pharmaceutical Research, 4: 227-232

[10] Bhattacharya, A.; Misra, B.N.; 2004, Prog. Polym. Sci., 29, 767-814

[11] De, Q.A.; Vargas, R.R.; Higa, O.Z.; Ribeiro, R.R.; Vitolo, M. J.; 2002, Appl. Poly.Sci., 84, 767

[12] Eurisk Assessment-Methyl Methacrylate, CAS No: 80-62-6, EINECS No: 201-297-1, FINAL REPORT, 2002

[13] Sheng, Q.N.; Fen, R.; Chao, H.; Peng, F. Z.; Xiao, H.W.; Jie, L.; Chang, S.Z.; 2011, Chinese Chem.Letters, 22(3), 370-373

[14] Vijay, K.S.; Namdev, B.S.; Prasannakumar, S.; Sherigara, B.S.; Aminabhavi, T.M.; 2011, Journal of Polymer Research, 18(3), 359-366

[15] Seniha,G.F.; Yusuf,Y.; A. Tuncer Erciyes.; 2006, Prog. Polym. Sci., 31, 633-670

[16] Sanmathi,C.S.; Prasannakumer,S.; Sherigara, B.S.; 2004, Bull. Mater. Sci., 27,(3), 243-249

[17] Tiemblo, P.; Laguna, M.F.; Garc1,F.; Garc1, J.M.; Riande, E Guzma'n, J.; 2004, Macromolecules, 37, 4156-4163

[18] Gatica, N.; Natali, F.; Alejandra,O.; Deodato, R.; 2005, J.Chil. Chem.Soc., 50, 581

[19] Wessling, R.A.; 1968, J. Appl. Polym. Sci., 12, 309-319

[20] Vijay, K.S.; Prasanna Kumar, S.; Musturappa, T.E.; Mahadevan, K.M.; Sherigara, B.S.; 2007,J. Macromolec. Sci., part A: Pure and Appl. Chemistry, 44, 1161-1169

[21] Gan, L.H.; Roshan, D.G.; Gan, Y.Y.; 1998, European Polymer Journal, 34( 1), 33-36

[22] Vijay, K.S.; Prasanna Kumar, S.; Sherigara, B.S.; Reddy, B.S.R.; Aminabhavi, T.M 3.; 2008, J. Macromol. Sci, part A: Pure and Appl. Chem, 45, 821-827

[23] Dong, S.; Wel, Y.; Zhang, Z.; 1999, J. Appl. Polym.Sci., 74, 516

[24] Pekel.N.; 2001, Eur. Polym. J., 37, 2443

[25] Rzaev, Z.M.O.; Guner, A.; Kibare, G.; Kalplan, H.C.; Asisi, A.; 2002, Eur. Polym. J., 38,1245

[26] Gatic, N.; Gargallo, L.; Radic, D.; 2002, Eur. Poly. J., 38, 1371 